\title{
Morphemic Acquisition Order Testing in Third-person Inflection and Plural Sequence in Krashen's Natural Order Hypothesis on Chinese International Students
}

\author{
Yu Bai ${ }^{1, a, *, \dagger}$ Ziqi Sun ${ }^{2, b, *, \dagger}$ Zhuang Yang ${ }^{3, c, ~}{ }^{*}, \dagger$ \\ ${ }^{1}$ Faculty of Arts and Science, Queen's University, Kingston, Ontario, K7L 3N6, Canada \\ ${ }^{2}$ College and Graduate School of Arts \& Sciences, University of Virginia, Charlottesville, Virginia, 22903, the United \\ States \\ ${ }^{3}$ Faculty of Art, The Chinese University of Hong Kong, City, Hong Kong, 999077, China \\ ${ }^{*}$ Corresponding author.Email: ${ }^{a} 17 y b 13 @ q u e e n s u . c a,{ }^{b}$ zs5bz@virginia.edu, ${ }^{c} 1155141461 @ l i n k . c u h k . e d u . h k$ \\ These authors contributed equally.
}

\begin{abstract}
Since Krashen first introduced Natural Order Hypothesis (NOH) in 1980, many researchers started to test it among participants from different cultural backgrounds. NOH stated that human beings have a certain universal order to acquire their second language (L2). However, recent research articles for NOH testing after 2010 are rare. Over this decade, students' learning environment and teachers' teaching methods are rapidly changing. Whether students' Natural Order for second language acquisition (SLA) still remains the same is the research topic for this paper. In this research, our target group is Chinese first language (L1) learners of English as an L2 who study in various English-speaking countries including Canada, Singapore, the United States, and the United Kingdom with abroad experience from 6 months to 8 years. Thirty interviews are collected to create a corpus and upon which to perform error analysis to test the comparative acquisition order of third-person inflection and plural. According to the comparison result of the percentage of errors made in third-person inflection and plural in the speech of one participant, the test subjects are categorized into three types. By comparing the number of test subjects in each category, our research concludes that this test strongly supports the hypothesis that third-person inflection occurs later than plural in the morphemic acquisition order. While probing into the reasons behind the number of test subjects in each category, this research discovered interesting findings which include the positive correlation between the length of studying abroad and the invisibility of acquisition order regarding the two target morphemes and possible interference of the place of residence during the interview to the test result. In addition, this research open the discussions on new norms of standard fixed phrases in the plural as a by-product of COVID-19. Furthermore, this research found and distinguished between different types of self-corrections in corpus while questioning the boundary between learned and acquired.
\end{abstract}

Keywords: Natural Order Hypothesis, Morphemic Acquisition Order, Error Analysis, Contrastive Analysis, Structured Communication, Second Language Acquisition, Chinese International Students.

\section{INTRODUCTION}

The debate around $\mathrm{NOH}$ is mysteriously quietening down, even though there is still so much to explore. What is a natural order in applied linguistics? What could be called natural order with confidence in applied linguistics? And how is the natural order a universal reality? Do we all agree? As scientific research continues shining light while venturing into the unknown, further possibilities reveal in plain sight. This research explores one of those possibilities with passion. Reflecting on past research methods, a new approach combining error analysis, contrastive analysis, and structured conversation is born to test the $\mathrm{NOH}$, specifically the comparative acquisition order of the third-person inflection and the plural. The thesis statement is that this research strongly supports the 
hypothesis that third-person inflection morpheme appears later in the acquisition order than plural.

\section{LITERATURE REVIEW}

\subsection{Historical Background}

Morpheme Order Studies (MOS) is a series of studies based on the assumption that there is a natural and universal order in morpheme acquisitions for all learners acquiring first and second languages [1]. To better enhance the understanding of this research, a summary of the historical development and methods used in the current MOS is presented.

The study began with Brown's research in 1962. The study focused on observing three preschool children's acquisition order of 14 different grammatical morphemes in L1 English [2]. His longitudinal research lasted for two years, and the principal data were the transcripts of the spontaneous speech recorded at least two hours for each child each month [2]. Mean Length of Utterance (MLU) was proposed by Brown in 1973, a measurement for calculating linguistic productivity of children's language acquisition; it collected 100 utterances of a child and divided the number of morphemes by the number of utterances; a higher MLU means a higher level of particular morpheme acquisitions proficiency [2]. In the end, he concluded that there is a similar acquisition order for children's L1 acquiring in grammatical morphemes [2].

Later, more and more scholars have concentrated on SLA in MOS. The central studies in this field mainly used Bilingual Syntax Measure (BSM) and Second Language Oral Production Exam (SLOPE) as their research methods to test subjects' L2 proficiency. In BSM, researchers ask simple questions about a number of easy and captivating pictures to extract target linguistic data. The SLOPE method requires subjects to write in a slot inside a half-completed sentence referring to the designated pictures. In 1973, Dulay and Burt first conducted cross-sectional research of Spanish children's L2 acquisition order of eight English grammatical morphemes [3]. They conducted cross-sectional research on Chinese and Spanish children's acquisition sequences for eleven English grammatical morphemes a year later. The result of acquisition sequences across the years for both L1 groups is similar, diminishing the importance of L1 as a factor in MOS [3]. In the same year, another cross-sectional research showed a similar sequence of morpheme acquisition for adults learning L2, and the study also supports that L1 does not affect MOS [4]. In 1976, Krashen, Sferlazza, Feldman, and Fathman moved forward to test more adults from different L1s [5].

\subsection{Natural Order Hypothesis}

Krashen suggested a "natural order" in the L2 morphemic acquisition independent of learners' L1 or their age, namely the Natural Order Hypothesis (NOH) in 1977 as a ground-breaking hypothesis [6]. He also suggested a Monitor Model in L2 acquisition, which classified L2 learning into two systems: conscious and subconscious. Krashen argues that "Subconscious learning requires meaningful interaction in the target language in which speakers are concerned not with the form of their utterances but with the messages they are conveying and understanding" [6]. In contrast, conscious learning greatly involves error correction and grammar rules applications [6]. Based on the two systems, Krashen suggested that "conscious learning is available to the performer only as a Monitor." In sum, to Krashen, the natural order in the morphemic acquisition is a manifestation of the acquired system, independently of contribution from the conscious grammar or the Monitor [6].

\subsection{The Conscious Grammar Problem in $\mathrm{NOH}$}

Some studies bring challenges to the NOH. In 1975 , Larsen-Freeman conducted research using a "grammartype" test, which is also termed "fill-in-the-blank" [7]. This research showed a different sequence in SLA morpheme acquisition order from the previous ones. In 1976, research led by Roger Andersen also showed a different sequence from Krashen's research [7]. The method adopted was a composition test on ESL adults in Puerto Rico.

On these points, Krashen stated that the common problem of such tests was the invitation of the use of conscious grammar and the Monitor [6]. He commented that "When performance is 'monitored', the natural order is disturbed", as the Natural Order reflects the true proficiency of acquisition. In contrast, the urge to use the Monitor disturbs it. When a "grammar-type" test is used, the participants' attention is purposefully directed to certain grammatical morphemes; therefore, the results do not reflect $\mathrm{NOH}$. The composition test also allows participants to correct grammar errors during the process, involving conscious grammar instead of testing subconscious grammar.

To demonstrate his conviction, Krashen conducted cross-sectional study research with other authors Butler, Birnbaum, and Robertson testing free written composition in 1978 [8]. In this Composition test, they asked the participants to write as much as possible and divided samples into two groups: (1) with a time limit (2) without time limit. The results obtained in both conditions proved the same order of acquisition and were similar to that in the adult oral tests in Krashen's 1974 research [6]. Krashen suggested that NOH still worked in both situations because the primary purpose of the test 
was to communicate instead of to perform. The participants did not use their conscious knowledge (the Monitor) to any great extent when communication is the issue [6].

\subsection{Research Planning Based on Previous Literatures}

\subsubsection{Design Control Factors: Age and L1}

Although age and L1 were considered peripheral in previous MOS, other researchers also offered their own academic opinions recently. In 2006, Carmen Muoz concluded that the morphemes are acquired in the same order independently of age, but the acquisition rates in different age groups are different [9]. In 2009, Luk and Shirai remarked that universality in morpheme acquisition does exist, but "the influence of the L1 is not minimal and has to be dealt with" [10]. Considering the potential influences of age and L1 in the research, we controlled both factors in our design. The L1 of all participants is the same, and the age difference is within four years old, the length of a typical college.

\subsubsection{Design Test Elements: Plural Morpheme and Third-Person Inflection Morpheme}

\subsubsection{Why Plural Morpheme and Third-Person Inflection Morpheme?}

Contrastive Analysis introduced by Carl in 1971 encourages researchers to insightfully compare the similarities and differences between people's first and second language [11]. In doing so, the error trend of people's second language use could be forecasted by contrastively analyzing their mother tongue.

In Chinese, there were no plurals and third-person inflection for both oral pattern and written pattern. Instead, Chinese speakers use quantifiers to express singular and plural nouns rather than changing the form of nouns by adding suffixes, compared to English. Chinese also has no third-person inflections, which is different from English.

Therefore, this research focuses on whether no plural and no third-person inflection form of Chinese could influence Chinese international students' acquiring order of English. Do Chinese international students have the same acquisition order as those from other cultures based on existing studies? Is it harder for Chinese international students to acquire third-person inflection and plural since they have never seen such language forms in their first language? Will the third-person inflection morpheme still be ranked significantly lower in acquisition order than plurals, according to previous research [12]?

\subsubsection{Define Plural and Third-Person Inflection}

Definitions of plural and third-person inflection used here are from the research of Burt and Dulay, which distinguishes between short plural (s) and long plural (es) [13]. The general difference between the two is that short plural is acquired earlier than long plural. Following the previous research by Burt and Dulay, this research also tests only the morphemic acquisition order of short plural (both the $/ \mathrm{s} /$ and $/ \mathrm{z} /$ allomorphs) [13]. Present indicative (third-person inflection) in Burt and Dulay's study is expected when "third-person singular noun or pronoun appear(s) in subject position (which is) immediately followed by the main verb." Two additional notes on third-person inflections are: "DOES and HAS used as main verbs were not included (...)"; and "cases of backto-back s's were omitted," such as she reads so much. This research follows these guidelines in designs and analysis.

\section{RESEARCH OBJECTIVE}

We found no oral research tests in recent studies of the morphemic acquisition order of Chinese L1 subjects despite extensive literature reviews. More importantly, no oral tests on this topic on Chinese international students of diverse backgrounds in various countries are found. Data from English learners with Mandarin as their native language are primarily collected from one single English-speaking country. Our research can fill in the gap in the current research on MOS.

\section{RESEARCH PROCEDURES}

\subsection{Test Subjects}

\subsubsection{Background Information on Test Subjects}

Thirty Chinese L2 learners are interviewed in this research. The age range of the test subjects is between 20 to 24 . They all experience a certain degree of community searching and identity building in a new environment while studying abroad. The test subjects chosen have study abroad experiences with a minimum length of six months and a maximum length of eight years. They have used and continue to use English as a necessary tool of communication in English-speaking countries. Their English immersion backgrounds are diverse. Specifically, three have study abroad experience in Singapore, eleven in Canada, one in the United Kingdom, thirteen in the United States, and two have studied in more than one English-speaking country.

\subsubsection{Research Emphasis on Diverse Education Backgrounds}

This mixture of diverse education backgrounds benefits the research because one of the common contributors of biases - teaching preferences under the 
same education system - is eliminated, which has been a recurrent shortcoming from past research [3][4]][7] [13]. Most research is conducted locally from a single institution or destination with test subjects from diverse international backgrounds if diversity is emphasized. The variety of subjects' backgrounds can be significantly compromised by the singularity of the possibility in their living environment. This particular research approaches differently from past research because the test subjects all grew up in China, but they choose to live in different English-speaking environments later. At the research point, some are in their country of study while some are in China. Diversity is emphasized and valued in our research.

\subsection{Interview Design}

\subsubsection{The Overview of the Interview}

The interview is conducted individually through telecommunication devices. The interview in total is two hours and 43 minutes, recorded for analysis through manual transcribing and error analysis. The result of the analysis is further collected and compiled for evaluation.

\subsubsection{Structured Communication}

Structured communication is preferred over unstructured communication for reasons of efficiency. Unstructured communication usually pairs with the longitudinal testing method, where one subject's progress is tracked through a long time by periodic updates [12]. The commitment and investment are high from both the researchers and the subjects. Unstructured communication involves non-specific discussions and relies on spontaneity. In comparison, structured communication allows data collection from a diverse population at a specific time with relatively minor commitment but instant relevant results. This research is designed to test the morphemic acquisition order of thirdperson inflection and plural with broad sample size and a significant representation.

\subsubsection{Interview Questions Design}

Interview questions (attached in Appendix) include three types: introduction and background, inquiries on habitual events, and free-response questions on global affairs. The first type of question is for essential information collection. The last two types of questions are designed to elicit responses with third-person inflections. No questions are explicitly designed to elicit plurals because plurals should not be rare in a conversation with changing topics. The data collection on plurals is sufficient, supporting the initial speculation that no particular plural-focused questions are needed. All test subjects completed all three types of questions with variations on the number of questions one attempted under one specific type. Multiple attempts are suggested by the researchers for the last two question types only when the test subjects fail to answer the guided questions with third-person inflections as designed.

\section{DATA ANALYSIS}

This research uses error analysis, which is "an analysis model which focuses on people's correct and incorrect utterances in order to describe learning of a language" [11]. Here, the learning aspect of the English language is the morphemic acquisition order of thirdperson inflection and plural. The "correct and incorrect utterance" refers to the separated grammatical mistakes of third-person inflection and plural from the grammatically correct speech. After transcribing, this separation process begins. Every mistake counts in error analysis, regardless of the overall performance. Therefore, we expect three results from the study of individual performance. In the speech of each test subject, the percentage of mistakes made in third-person inflection is 1) more than 2) less than or 3 ) equal to the percentage of mistakes made in plurals. For the convenience of reference, the three results are labelled as $\mathrm{T}$, $\mathrm{P}$, and $\mathrm{M}$, respectively, in short for third-person inflection bias, plural bias, and medium ground in between from each test subject.

\section{RESULTS AND DISCUSSIONS}

\subsection{Results}

The individual results of $\mathrm{T}, \mathrm{P}$, and $\mathrm{M}$, are compiled to compare the total number of $\mathrm{T}, \mathrm{P}$, and $\mathrm{M}$ in the sample. Among the 30 test subjects, $\mathrm{T}$ to $\mathrm{P}$ to $\mathrm{M}$ ratio is 18: 7: 5 . Overall, $\mathrm{T}$ is represented around 2.6 times more than $\mathrm{P}$. The significance of the difference between the number of $\mathrm{T}$ and $\mathrm{P}$ shows that the research conducted is strong enough to support the existing hypothesis or offer an alternative hypothesis. The research result strongly supports the hypothesis that the acquisition of thirdperson inflection comes later than plurals because more people make mistakes in third-person inflection than plurals.

\subsection{Discussions}

\subsubsection{Overview}

As shown in Figure 1.1, T, P, and M percentages are $60 \%, 23.3 \%$, and $16.7 \%$, respectively. 


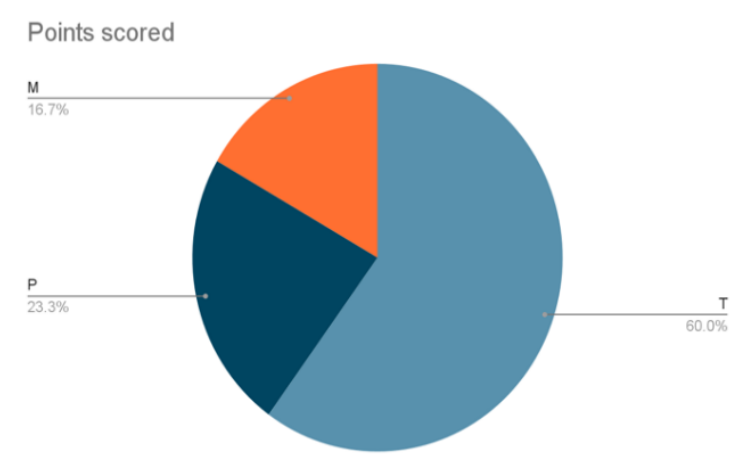

Figure 1. Distribution of T, P, and M

$\mathrm{M}$ can be further broken down into two cases: the number of mistakes made in third-person inflection is equal to the number of mistakes made in plurals 1) and both equal to zero 2) but not equal to zero. The two cases of $\mathrm{M}$ are termed $\mathrm{M} 1$ and $\mathrm{M} 2$ in short. M1 has 1 occurrence and accounts for $20 \%$ in M; M2 has 4 cases and $80 \%$ in $\mathrm{M}$.

\subsubsection{Other Factors}

\subsubsection{Length of Overseas Studying}

In Table 1, the years abroad is compared across test subjects labelled as M1, M2, T, and P. The results that stand out are from M2, where the average, median, and mode years abroad is significantly higher than those from $\mathrm{M} 1, \mathrm{~T}$, or P. There are reasons to believe that there is a positive relationship between the number of years studying abroad and the competency of the English language, thus the invisibility of the acquisition order of the target morphemes, which are early structures for these four test subjects.

Table1. Years Abroad Comparison Among M1, M2, T, and $\mathrm{P}$

\begin{tabular}{|c|c|c|c|c|c|}
\hline Type & Total & $\begin{array}{l}\text { Average } \\
\text { Yrs }\end{array}$ & $\begin{array}{l}\text { Mediant } \\
\text { Yrs }\end{array}$ & $\begin{array}{l}\text { Mode } \\
\text { Yrs }\end{array}$ & $\begin{array}{l}\text { Range } \\
\text { Yrs }\end{array}$ \\
\hline$\overline{\mathrm{M} 1}$ & 1 & 3 & 3 & 3 & 3 \\
\hline M2 & 4 & 7 & 7.5 & 8 & $5-8$ \\
\hline $\mathrm{T}$ & 18 & 3.8 & 3 & 2 & $0.5-8$ \\
\hline $\mathrm{P}$ & 7 & 3.36 & 2.5 & 2 & $2-6$ \\
\hline
\end{tabular}

\subsubsection{Place of Residence During Interview}

Ideally, data from international students should be collected while they are in their respective countries of study. Still, under the influence of global politics and travel restrictions under COVID-19, international students are mostly back in their home country for safety reasons. The native environment is suspected to have implications on their performance as the interview is conducted in English, a foreign language, instead of a second language to the test subject at the point of the interview. As Table 2 has shown, more T-type subjects are in their home country than in the country of study. In contrast, more M2-type subjects are in their countries of study than in their home country.

We hope to collect more data from test subjects in the country of study for cross-analysis. The need for such future data collection arises from a postulation that the performance in the interviews might not reflect the acquisition of the specific morphemes but the environmental influence.

Table 2. Place of Residence During Interview

\begin{tabular}{llll}
\hline Type & In China & $\begin{array}{l}\text { In Country of Total } \\
\text { Study }\end{array}$ \\
\hline M1 & 1 & 0 & 1 \\
M2 & 1 & 3 & 4 \\
T & 13 & 5 & 18 \\
P & 3 & 4 & 7 \\
\hline
\end{tabular}

\section{CHALLENGES IN RESEARCH DATA} ANALYSIS

\subsection{Plurals as Fixed Morphemes}

Not all plurals reflect the morphemic acquisition. A distinction between viable and nonviable test data is made "because of the intricate relationship between semantics and morphemes in fixed phrases" in Burt and Dulay [13, 14]. The examples of plurals "learned as unsegmented wholes" provided by Burt and Dulay are "scissors" and "do dishes". The most common fixed plural phrase in our research is "put on some clothes," which does not count towards plural use. However, phrases such as "take (online) courses" and "take courses (online)" also occur in high frequency but are debatable as fixed morphemes. Considering COVID-19, taking online courses and taking courses online are becoming mundane phrases, perhaps independent of the morphemic processing of pluralization for international students.

\subsection{Tense Misuse and Inconsistencies}

The most significant source of viable data for thirdperson inflection is from tense misuse and inconsistencies. Surprisingly, inquiries of habitual activities are answered frequently in the future tense and past tense or a mixture of tenses. Below shown in table 3 are examples for each category. 
Table 3. Examples of Tense Misuse and Inconsistencies

\begin{tabular}{lll}
\hline Mistake Types & $\begin{array}{l}\text { Test } \\
\text { Subject }\end{array}$ & Example \\
\hline Future Tense & NO.5 & She will walk the dog. \\
Past Tense & NO.3 & $\begin{array}{l}\text { She usually came home } \\
\text { around 5. }\end{array}$ \\
Modal Verb & NO.7 & $\begin{array}{l}\text { She would cook } \\
\text { breakfast. }\end{array}$ \\
Mixture of Tense & NO.9 & $\begin{array}{l}\text { Every day he will wake } \\
\text { up. He went into the } \\
\text { bathroom to take a } \\
\text { shower. He will just } \\
\text { cook by himself. }\end{array}$ \\
\hline
\end{tabular}

Participants' confusions over tense use negatively impact data collection, as the uninflected verbs following auxiliary verbs "will" and "would" could not count towards correct or incorrect use of third-person inflections. In addition, because our research does not investigate the acquisition order of all morphemes but only third-person inflection and plural, the interference of the acquisition of other morphemes with tenses such as future and past tense can pose threats to data collection.

\subsection{Self-Corrections}

Self-corrections occurred in the structured communications, reflecting participants' conscious awareness for accuracy and the inference of the Monitor. Table 4 below shows the specific examples.

Table 4. Examples of Self-Corrections

\begin{tabular}{lll}
\hline $\begin{array}{l}\text { Self-Correction } \\
\text { Type }\end{array}$ & $\begin{array}{l}\text { Test } \\
\text { Subject }\end{array}$ & Example \\
\hline Motion & NO. 2 & $\begin{array}{l}\text { He went home } \\
(1.2 \mathrm{~s}) \text { no, he } \\
\text { came home... }\end{array}$ \\
Monitor (success) & NO. 8 & $\begin{array}{l}\text { She have }(0.7 \mathrm{~s}) \\
\text { she has seen... }\end{array}$ \\
Monitor (failure) & NO. 8 & $\begin{array}{l}\text { She went to } \\
(0.8 \mathrm{~s}) \text { she go to } \\
\text { sleep... }\end{array}$ \\
\hline
\end{tabular}

First, a certain re-categorization of the motion of movement relative to the speaker is captured in the speech of test subject 2. Second, a third-person inflectional change occurred from "she have" to "she has seen", reflecting not the success of acquisition but the success of learning. Third, a change of a verb conjugation from one tense into another is captured, although changed incorrectly. Here, the question of whether the Monitor is used when the test subject made self-correction stands. Further research on the Monitor is needed to comprehensively analyse what cases its cognitive effect on grammar applies to morphemic acquisition.

\section{CONCLUSION}

Our research strongly supports the hypothesis that third-person inflection occurs later than plural in the morphemic acquisition order by conducting interviews with structured conversations and building a corpus on the target group of Chinese international students within a small age difference, inspired by previous research findings on L1 and age. This improved research method compared to previous research methods mentioned in the literature review, including MLU, BSM, SLOPE, grammar-type test, and composition test, which allows greater reliability and supports the credibility of our research. Interesting findings from this research include the positive correlations between the length of studying abroad and the invisibility of acquisition order regarding the two target morphemes and possible interference of the place of residence during the interview to the test result such that almost three-quarters of type $\mathrm{T}$ occurs when the participants are in their home country. Our research also opens the discussions on expanding the list of fixed phrases in the plural as what counts as fixed phrases is changing when new norms are established in this pandemic. Furthermore, this research found and distinguished between different types of self-corrections in corpus while probing into the cognitive effect of the Monitor on the morphemic acquisition, which is beyond the scope of this paper but deserves academic attention and requires further research.

Generally, this study fills in the gap by collecting and analysing data on the morphemic acquisition by Chinese international students in second language learning. Although every sample in this study was analysed in great detail and could show a trend, for future research, it will be better to have a larger sample size to cross analyse, a more accurately defined "success" in SLA in relation to MOS and have complementary research methods to avoid contingency of the research involving one-time data collections.

Last but not least, the distinctions between the Monitor interference and a simple slip of the tongue can be unclear and fairly subjective. In theory, the procedure following the identification of one or the other is straightforward. In practice, it is almost impossible to draw the line between the Monitor System and a correction after a slip of the tongue. The situation is further complicated by the possibility of both inferences in one utterance. The distinction has to be made based on the researchers' intuitions after listening to the recordings several times to categorize the validity of the particular instance of self-correction. 


\section{APPENDIX}

Interview Questions below:

The three types of interview questions are listed

1. Describe the daily routine of a person you are familiar with. This person could be your friend, your roommate, or your family member.

2. Describe your favourite TV show or film. Who are the characters? What is the plot?

3. What is the personal impact of COVID-19 on you and your family? Could you comment on the social and global implications of COVID-19?

\section{REFERENCES}

[1] Ramos Feijoo, J. (2021). Morpheme Order Studies: A Descriptive Study in English as a Second Language.

[2] Brown, R. (1973). A First Language. Cambridge, MA: Harvard University Press, 1973.

[3] Dulay, H.C., \& Burt, M.K. (1974). Natural Sequences in Child Second Language Acquisition. Language Learning, 24, 37-53.

[4] Bailey, N., Madden, C., \& Krashen, S. D. (1974). Is There A "Natural Sequence" In Adult Second Language Learning? Language Learning, 24(2), 235-243.

[5] Krashen, S. D., Sferlazza, V., Feldman, L., \& Fathman, A. K. (1976). Adult Performance on the SLOPE Test: More Evidence for a Natural Sequence in Adult Second Language Acquisition. Language Learning, 26(1), 145-151.

[6] Krashen, S. D. (1981). Second Language Acquisition and Second Language Learning. Oxford: Pergamon.

[7] Fathman, A. (1975). Language background, age and the order of acquisition of English structures. In M. K. Burt \& H. C. Dulay (Eds.), On TESOL'75: New directions in second language learning, teaching and bilingual education (pp. 33-43). Washington, DC: TESOL.

[8] Krashen, S. D. (1978). Is the "Natural Order" an Artifact of the Bilingual Syntax Measure? Language Learning, 28(1), 187-191.

[9] Muñoz, C. (2006). Accuracy Orders, Rate of Learning and Age in Morphological Acquisition. In C. Muñoz (Ed.), Age and the Rate of Foreign Language Learning (pp. 107-126). Buffalo: Multilingual Matters.
[10] Luk, Z.P., \& Shirai Y. (2009). Is the Acquisition Order of Grammatical Morphemes Impervious to L1 Knowledge? Evidence from the Acquisition of Plural $-\mathrm{s}$, Articles, and Possessive 's. Language Learning, 59, 721-754.

[11] Khansir, Ali Akbar. (2012). Error analysis and second language acquisition. Theory and Practice in Language Studies, Vol. 2, No. 5, pp. 1027-1032.

[12] Saville-Troike, M. (2012). Introducing Second Language Acquisition (2nd ed., Cambridge, Introductions to Language and Linguistics). Cambridge: Cambridge University Press.

[13] Burt, M. K., \& Dulay, H. C. (1980). On acquisition orders. In S.W. Felix (Ed.), Second language development: Trends and issues (pp. 265-327). Tübingen, Germany: Gunter Narr..

[14] Larsen-Freeman, D. E. (1975). The acquisition of grammatical morphemes by adult ESL students. TESOL Quarterly, 9, 409-419. 